\title{
Transitional relation exploration for typical loess geomorphologic types based on slope spectrum characteristics
}

\author{
S. Zhao ${ }^{1}$ and W. Cheng ${ }^{2}$ \\ ${ }^{1}$ Department of Surveying and Mapping, College of Mining Technology, Taiyuan University of Technology, \\ Taiyuan 030024, China \\ ${ }^{2}$ State Key Laboratory of Resources and Environmental Information System, Institute of Geographic Sciences \\ and Natural Resources Research, CAS, Beijing 100101, China
}

Correspondence to: S. Zhao (zhaoshangmin@ tyut.edu.cn)

Received: 26 January 2014 - Published in Earth Surf. Dynam. Discuss.: 18 February 2014

Revised: 5 July 2014 - Accepted: 20 July 2014 - Published: 19 August 2014

\begin{abstract}
Based on the Chinese Geomorphologic Database at 1:1000 000 scales, the distribution of the typical loess geomorphologic types (such as the loess tableland, loess ridge and loess knoll) is acquired in the Loess Plateau of China. Then, based on the SRTM (Shuttle Radar Topography Mission) digital elevation model (DEM) data and topographic analysis methods, the slope spectrums are computed for the typical loess geomorphologic types and their subtypes. Through achieving the tendency line of the slope spectrum and analysing the slope spectrum characteristics of the loess typical geomorphologic types, the transitional relationships are explored: (1) the general rule is that loess tableland transitions to loess ridge, and then to loess knoll. (2) The specific relationships for the subtypes are as follows: in loess tableland, the transition is from loess terrace to complete tableland, then to residual tableland, and finally to beam tableland. In the loess ridge, the transition is from oblique ridge to knoll ridge, and the final stage is the loess knoll.
\end{abstract}

\section{Introduction}

Topography is formed through relief-generation processes (such as uplift and stream incision) and slope-driven denudation processes, so the resulting topographic slopes can gives clues for these processes, and many topographic studies are carried out using slope distributions to explore these processes (Wolinsky and Pratson, 2005). For example, early studies focused on the hill slope profiles and modal characteristics slopes (Strahler, 1956; Carson, 1971; Anderson et al., 1980). Subsequent studies mainly attempted to use slope statistics from natural and simulated digital elevation models (DEMs) to relate the topography to geomorphologic processes (Burbank, 1992; Roering et al., 1999; Iwahashi et al., 2001). Finally, recent studies have mainly taken slope as an important topographic factor for characterizing and automatically classifying the landform types (Crevenna et al., 2005; Bue and Stepinski, 2006; Tang and Li, 2008).
This study takes the Loess Plateau of China as an experimental area, which attracts world attention in geographic research because of its unique geomorphologic features. In the Loess Plateau, the slope spectrum index is applied to study the loess geomorphology (Tang et al., 2008). The slope spectrum, as a microscopic terrain index, can reveal macro-geomorphologic features, which makes it a valuable topographic index in geomorphologic research (Tang et al., 2005).

In previous studies, loess geomorphology has been classified and characterized by using the slope spectrum index (Li et al., 2007; Wang et al., 2008; Zhou et al., 2010). The achievement of $1: 1000000$ scales in the Chinese Geomorphologic Database (CGD) provides the distribution of the loess geomorphologic types (Cheng et al., 2011a). As to the slope spectrum index, it can be computed based on digital elevation model (DEM) data, which, in this study, are the Shuttle Radar Topography Mission (SRTM) data. 


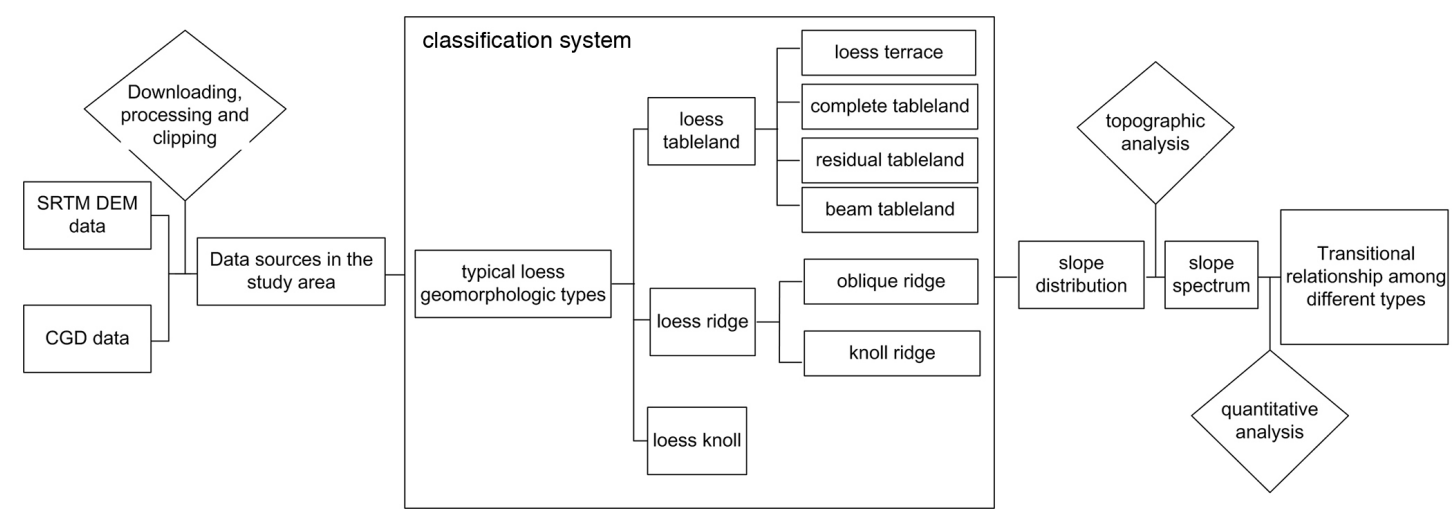

Figure 1. The workflows in this research.

Hence, this study aims to analyse the characteristics of the slope spectrums of the typical loess geomorphologic types using CGD and SRTM DEM data, and then explore the transitional relationships among the types and their subtypes based on the changing rules of slope characteristics.

\section{Study area and data sources}

\subsection{Study area}

This study selects the Loess Plateau of China as the study area. Located in the upper and middle reaches of the Yellow River, the Loess Plateau is on the west side of Taihang Mountain, the east side of the Qinghai-Tibet Plateau, the north side of Qinling Mountain and the south side of the Mongolian Plateau. The Loess Plateau is one of the four largest plateaus in China, and the widest and deepest loess in the world is distributed within it, forming as a result the most typical loess geomorphology. Loess geomorphology has a close relation with soil erosion, which is the one of the most serious problems for ecological and environmental safety in the Loess Plateau. Thus research on loess geomorphology has both scientific significance and economic importance.

\subsection{Data sources}

The main data sources used in this study are from the CGD at $1: 1000000$ scales and the SRTM DEM data.

The CGD data at 1:1000000 scales were recently achieved by using remote sensing visual interpretation and geographic information system methods from multi-source data, such as remote sensing images, SRTM3 DEM data, published geomorphologic maps, geologic data, geographic base data, etc. (Cheng et al., 2011a). These data are the source data to compile the 1:1000000 set of geomorphologic atlases of China (Li et al., 2009) and can be divided into seven layers: relief and altitude, genesis, sub-genesis, morphology, micro-morphology, slope and aspect, and material and lithology (Cheng et al., 2011b). In this study, the fourth

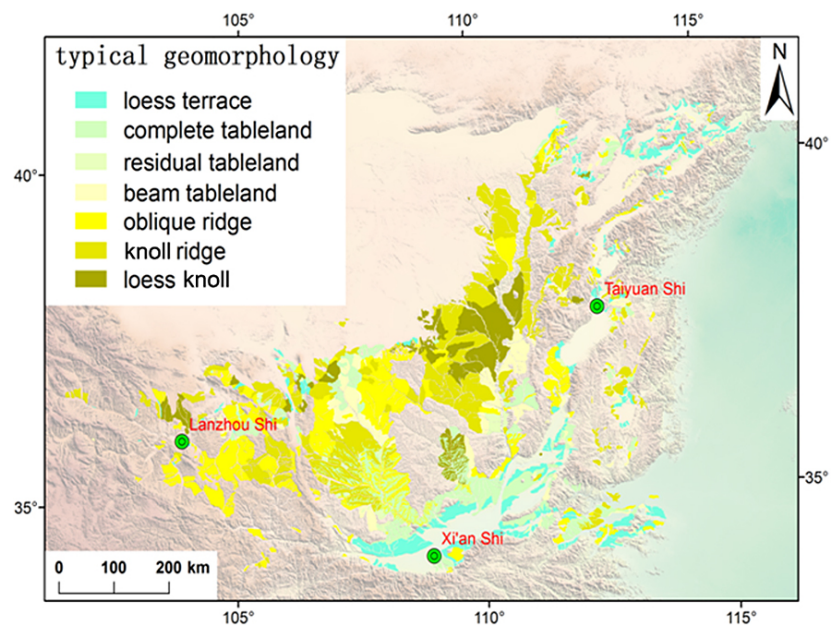

Figure 2. Typical loess geomorphology distribution in the Loess Plateau.

layer (morphology) and the fifth layer (micro-morphology) are used to acquire the distribution of the typical loess geomorphologic types and their subtypes.

The SRTM DEM data used here are the SRTM3 DEM data, which have $3^{\circ}$ spatial resolution (SRTM3) and are processed by the Consortium for Spatial Information of the Consultative Group for International Agricultural Research. It can provide continuous elevation surface information and wide coverage $\left(60^{\circ} \mathrm{N}-56^{\circ} \mathrm{S}\right)$, and as a result it has been used in many research fields. In this study, the SRTM3 DEM data are the version 4 data, and they are used to compute the slope spectrums for the typical loess geomorphologic types and their subtypes.

\section{Methodology}

The workflow of this study is shown in the Fig. 1.

This workflow shows the following: the main data sources (CGD data and SRTM3 DEM data) are firstly downloaded, 


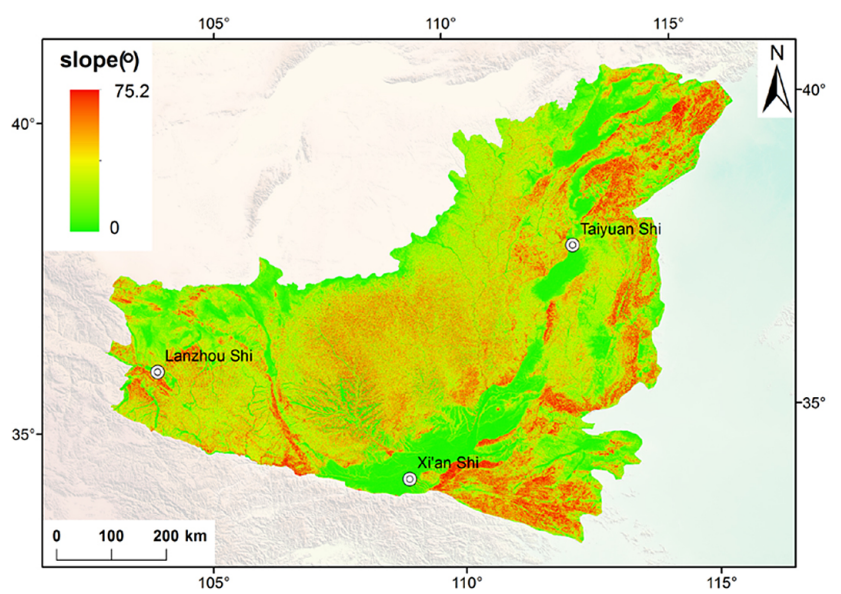

Figure 3. Slope distribution status in the Loess Plateau of China.

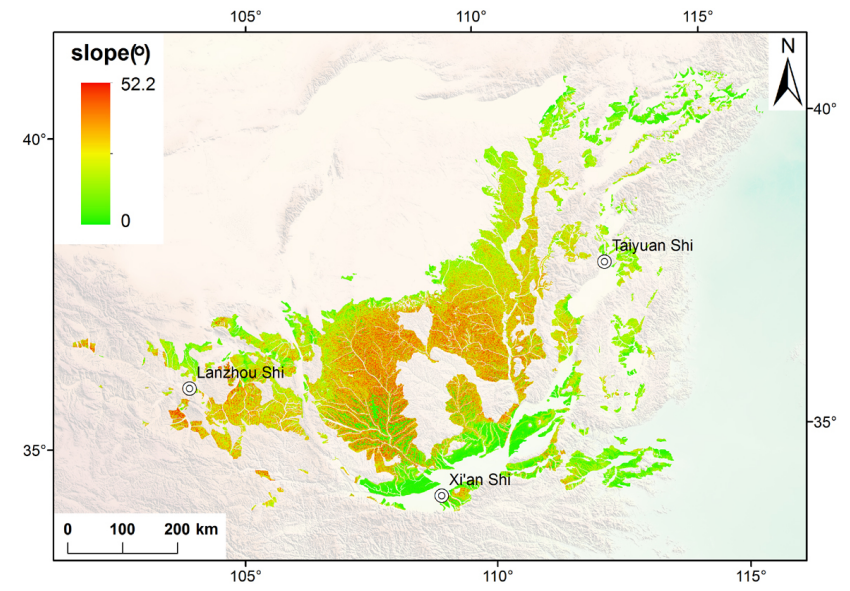

Figure 4. Slope distribution status in the typical loess geomorphologic area of the Loess Plateau.

processed and clipped; then, based on the CGD data, the distribution of the typical loess geomorphologic types and their subtypes is acquired, and the slope spectrums are computed for these geomorphologic types using SRTM3 DEM data and the topographic analysis method; finally, after the quantitative analysis to the characteristics of the slope spectrums (such as the tendency line, the regression equation and its corresponding $R^{2}$ ), the transitional relationship is achieved.

\subsection{Acquisition of the distribution of the typical loess geomorphologic types and their subtypes}

The typical loess geomorphology types are loess tableland, loess ridge and loess knoll. The distribution of these typical loess geomorphologic types is determined using the CGD data. The areas covered by the three types are $6.52 \times 10^{4}$, $9.12 \times 10^{4}$ and $1.91 \times 10^{4} \mathrm{~km}^{2}$, respectively.

The transitional rule among typical loess geomorphologic types is widely acknowledged as from loess tableland to loess
Table 1. Numerical statistics for the slope of different geomorphologic units $\left(^{\circ}\right)$.

\begin{tabular}{lcccc}
\hline Geomorphologic unit & Min & Max & Mean & $\begin{array}{c}\text { Standard } \\
\text { deviation }\end{array}$ \\
\hline Loess Plateau & 0 & 75.2 & 10.7 & 8.0 \\
Typical geomorphologic & 0 & 52.2 & 9.8 & 6.7 \\
area & & & & \\
Loess tableland & 0 & 51.0 & 7.1 & 6.7 \\
Loess ridge & 0 & 52.2 & 11.5 & 6.2 \\
Loess knoll & 0 & 46.8 & 10.6 & 5.8 \\
\hline
\end{tabular}

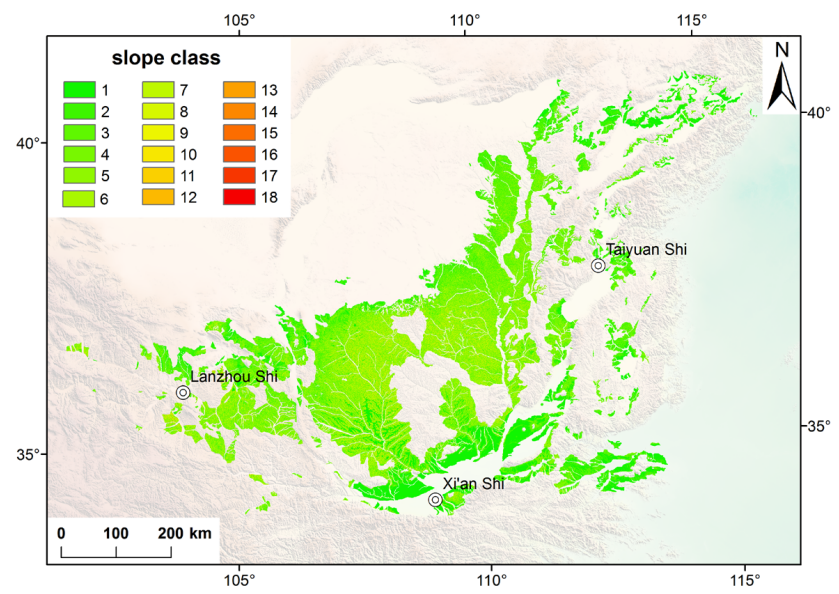

Figure 5. Slope class distribution status in the typical loess geomorphologic area of the Loess Plateau.

ridge and finally to loess knoll (Sang et al., 2007). Hence, in this study, more attention is paid to the transitional rules of the subtypes of typical loess geomorphology.

Considering the distribution areas and situations of the typical loess geomorphology types, the loess tableland is divided into four subtypes: loess terrace, complete tableland, residual tableland and beam tableland. The loess ridge is divided into oblique ridge and knoll ridge, and the loess knoll is not divided further. From the CGD data, the distribution of the subtypes of the typical loess geomorphology can be acquired and is shown in Fig. 2.

Figure 2 shows the distribution of the typical loess geomorphology: loess tableland is mainly distributed in the northern part of the city of $\mathrm{Xi}$ 'an and eastern part of the city of Lanzhou; in addition, sparse distribution can be seen around the city of Taiyuan. The loess ridge has the greatest area, and is mainly distributed in the eastern part of Lanzhou and western part of Taiyuan. Loess knoll has the least area, and is distributed in the western part of Taiyuan, the northern part of Xi' an, and around Lanzhou.

The acquisition of the distribution of the typical loess geomorphology provides the chance to compute the slope spectrum index for each type. 
Table 2. Distribution status of the slope intervals for the typical loess geomorphologic types.

\begin{tabular}{rrrrrrr}
\hline \multirow{2}{*}{ Slope interval $\left(^{\circ}\right)$} & \multicolumn{2}{c}{ Loess tableland } & \multicolumn{2}{c}{ Loess ridge } & \multicolumn{2}{c}{ Loess knoll } \\
\cline { 2 - 7 } & Percentage & Grid number & Percentage & Grid number & Percentage & Grid number \\
\hline $0-3$ & 39 & 3481883 & 6 & 728129 & 7 & 195155 \\
$3-6$ & 18 & 1608957 & 15 & 1832410 & 16 & 422065 \\
$6-9$ & 12 & 1054711 & 19 & 2333408 & 20 & 511864 \\
$9-12$ & 9 & 805219 & 18 & 2253837 & 19 & 490007 \\
$12-15$ & 7 & 647609 & 15 & 1896942 & 15 & 401575 \\
$15-18$ & 6 & 509414 & 11 & 1408602 & 11 & 281653 \\
$18-21$ & 4 & 365281 & 8 & 952910 & 6 & 168136 \\
$21-24$ & 3 & 229533 & 5 & 571302 & 3 & 84814 \\
$24-27$ & 1 & 121041 & 2 & 287704 & 1 & 34178 \\
$27-30$ & 1 & 52343 & 1 & 120561 & 0 & 10974 \\
$30-33$ & 0 & 18310 & 0 & 41779 & 0 & 2870 \\
$33-36$ & 0 & 5269 & 0 & 11749 & 0 & 579 \\
$36-39$ & 0 & 1415 & 0 & 2543 & 0 & 103 \\
$39-42$ & 0 & 324 & 0 & 577 & 0 & 28 \\
$42-45$ & 0 & 98 & 0 & 160 & 0 & 6 \\
$45-48$ & 0 & 15 & 0 & 52 & 0 & 1 \\
$48-51$ & 0 & 0 & 0 & 11 & & 2604008 \\
$51-54$ & 0 & 1 & 0 & & 1 & 100 \\
\hline Total & 100 & 8901423 & 100 & 12442677 & & 2 \\
\hline
\end{tabular}

Table 3. Distribution status of the slope intervals for the subtypes of the loess tableland.

\begin{tabular}{|c|c|c|c|c|c|c|c|c|}
\hline \multirow{2}{*}{ Slope interval $\left({ }^{\circ}\right)$} & \multicolumn{2}{|c|}{ Loess terrace } & \multicolumn{2}{|c|}{ Complete tableland } & \multicolumn{2}{|c|}{ Residual tableland } & \multicolumn{2}{|c|}{ Beam tableland } \\
\hline & Percentage & Grid number & Percentage & Grid number & Percentage & Grid number & Percentage & Grid number \\
\hline $0-3$ & 65 & 1713075 & 41 & 1568793 & 10 & 36401 & 8 & 163851 \\
\hline $3-6$ & 20 & 516158 & 19 & 737272 & 15 & 56426 & 15 & 297644 \\
\hline $6-9$ & 8 & 211427 & 12 & 467274 & 15 & 58501 & 16 & 316833 \\
\hline $9-12$ & 4 & 100710 & 9 & 342276 & 15 & 55785 & 15 & 306259 \\
\hline $12-15$ & 2 & 51825 & 7 & 258675 & 14 & 51875 & 14 & 285322 \\
\hline $15-18$ & 1 & 27116 & 5 & 194177 & 12 & 44530 & 12 & 243966 \\
\hline $18-21$ & 1 & 13296 & 4 & 135348 & 9 & 34529 & 9 & 182496 \\
\hline $21-24$ & 0 & 6507 & 2 & 83790 & 6 & 22236 & 6 & 117388 \\
\hline $24-27$ & 0 & 2992 & 1 & 43770 & 3 & 11469 & 3 & 63067 \\
\hline $27-30$ & 0 & 1433 & 0 & 18460 & 1 & 4503 & 1 & 28140 \\
\hline $30-33$ & 0 & 598 & 0 & 5728 & 0 & 1466 & 1 & 10578 \\
\hline $33-36$ & 0 & 226 & 0 & 1315 & 0 & 291 & 0 & 3470 \\
\hline $36-39$ & 0 & 76 & 0 & 240 & 0 & 31 & 0 & 1084 \\
\hline $39-42$ & 0 & 23 & 0 & 20 & 0 & 1 & 0 & 285 \\
\hline $42-45$ & 0 & 11 & 0 & 1 & & & 0 & 85 \\
\hline $45-48$ & 0 & 2 & & & & & 0 & 13 \\
\hline $48-51$ & 0 & 0 & & & & & & \\
\hline $51-54$ & 0 & 1 & & & & & & \\
\hline Total & 100 & 2645476 & 100 & 3857139 & 100 & 378044 & 100 & 2020481 \\
\hline
\end{tabular}

\subsection{Slope spectrum computation for the typical loess geomorphologic types and their subtypes}

Based on SRTM3 DEM data and the topographic analysis method, the slope distribution status is computed for the whole Loess Plateau, and the result is shown in Fig. 3.

Through clipping the slope distribution map for the whole Loess Plateau by the distribution area of the typical loess ge- omorphologic types, the slope distribution status in the typical loess geomorphologic area of the Loess Plateau is acquired, which is shown in Fig. 4.

Based on Figs. 3 and 4, the numerical statistics can be applied to the slope distribution status of the whole Loess Plateau, the typical loess geomorphology area, the loess tableland area, the loess ridge and the loess knoll; the results of this are shown in Table 1. 


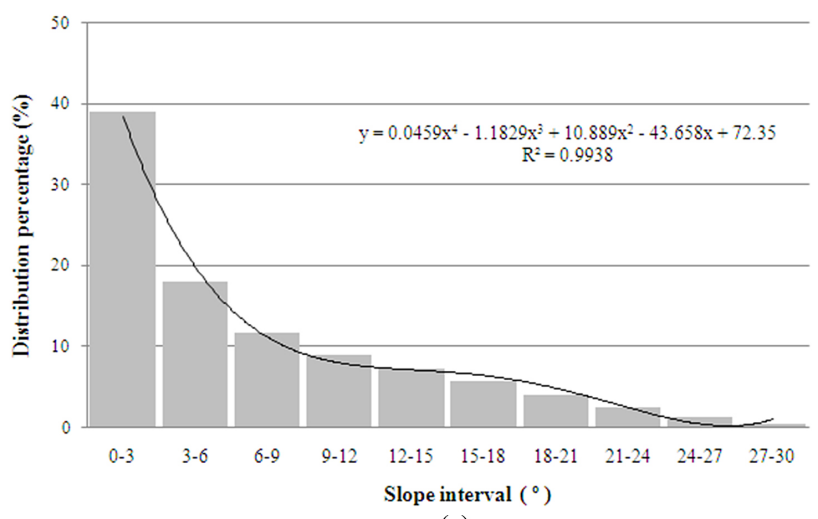

(a)

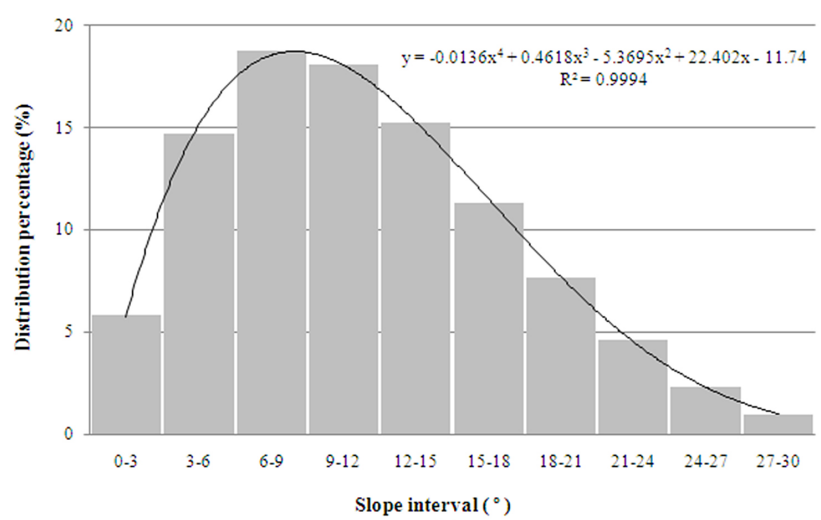

(b)

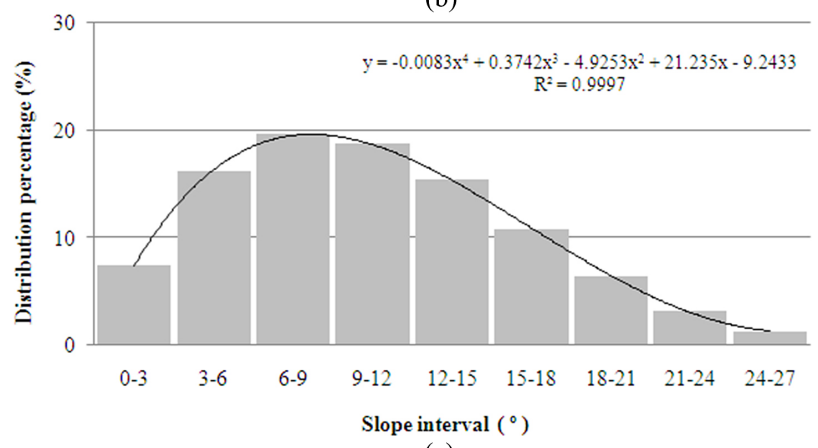

(c)

Figure 6. Slope spectrum and its quantitative analysis for the typical loess geomorphologic types. (a) Loess tableland, (b) loess ridge and (c) loess knoll.

Table 1 gives the maximum, minimum, mean and standard deviation values for all geomorphologic units, and shows the general slope distribution discrepancy among the geomorphologic units.

In order to quantitatively analyse the slope distribution status among all typical loess geomorphologic types, the slope is classified with an interval of $3^{\circ}$, which is applicable in slope spectrum studies (Zhu and $\mathrm{Li}, 2009$ ). The slope class distribution status in the typical loess geomorphologic area can be computed, and the results are shown in Fig. 5.

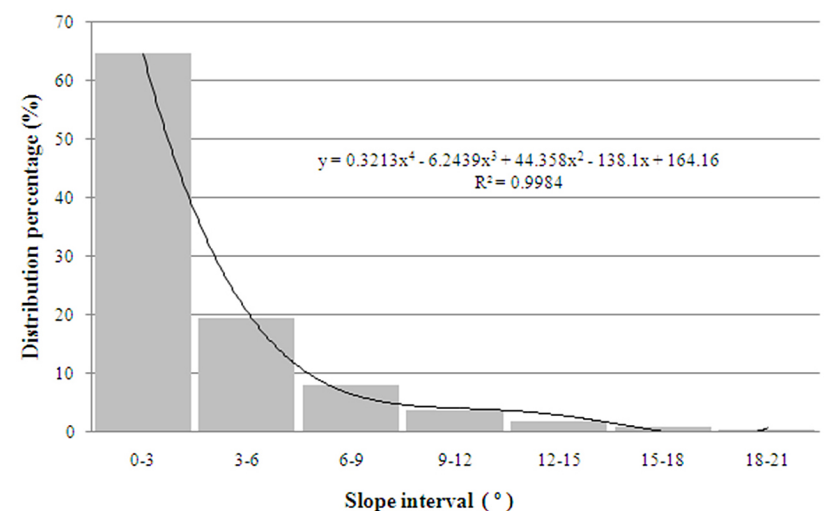

(a)

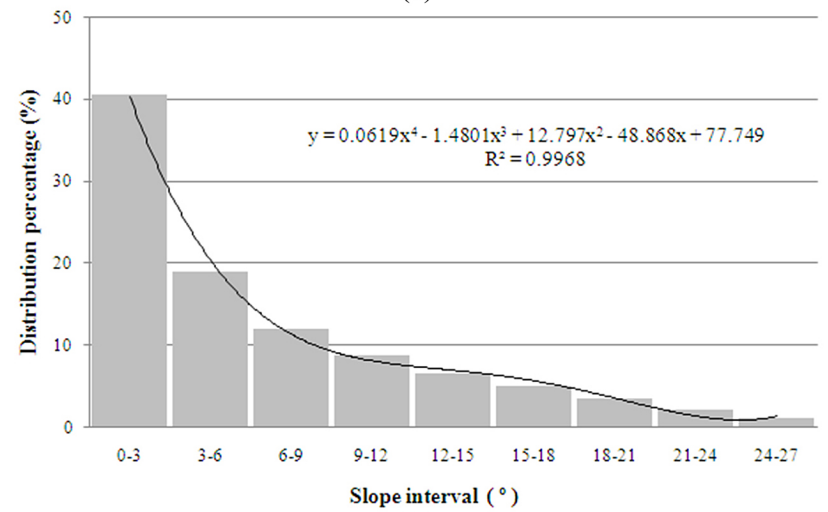

(b)

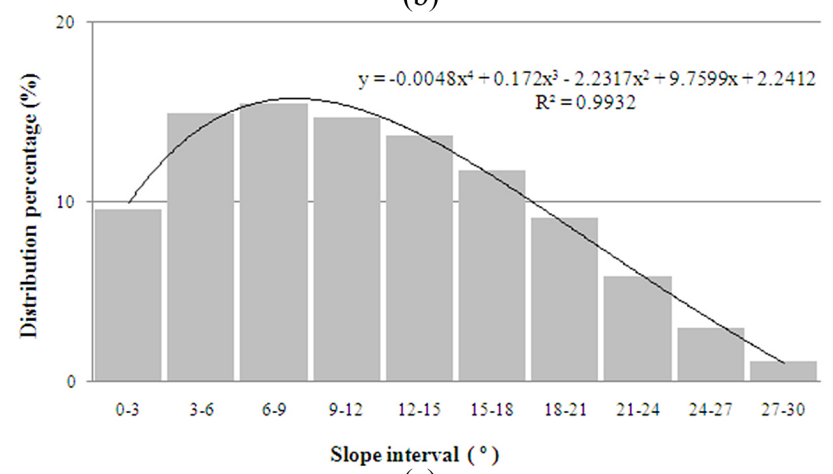

(c)

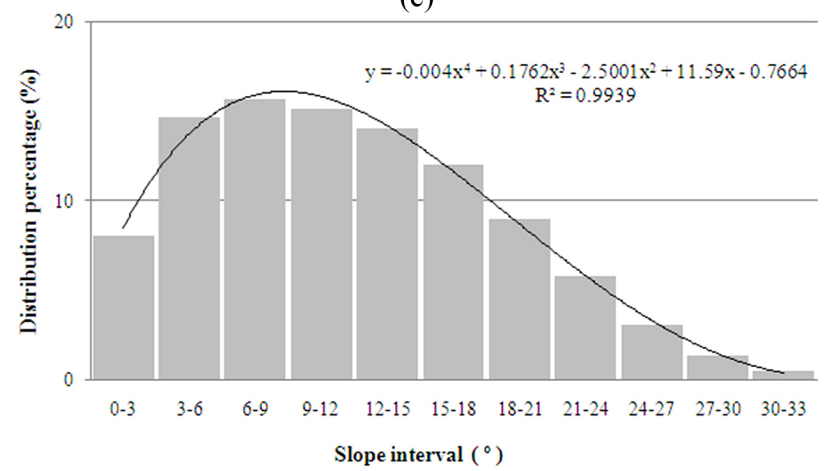

(d)

Figure 7. Slope spectrum and its quantitative analysis for the subtypes of the loess tableland. (a) Loess terrace, (b) complete tableland, (c) residual tableland and (d) beam tableland. 


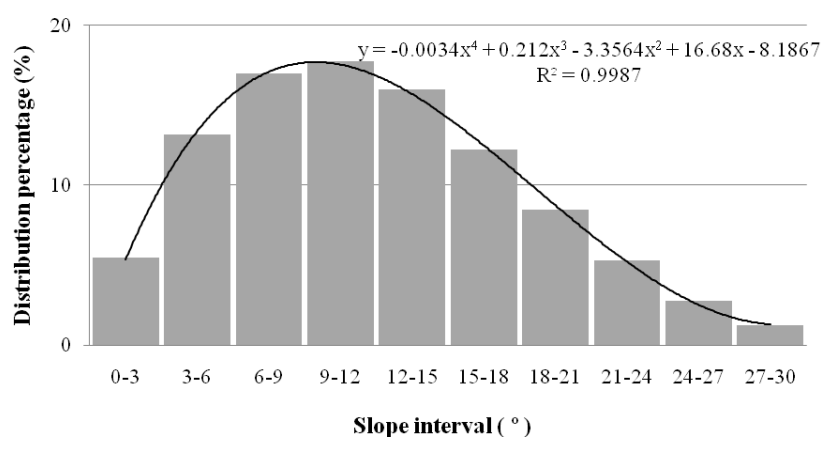

(a)

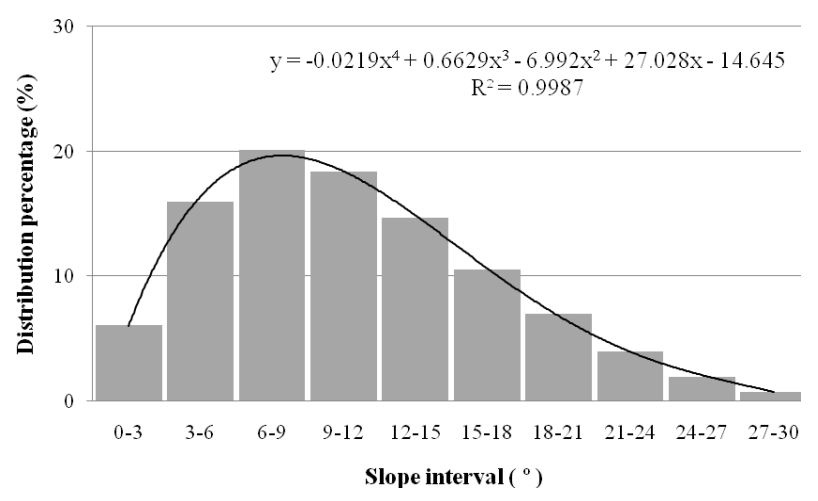

(b)

Figure 8. Slope spectrum and its quantitative analysis for the loess ridge. (a) Oblique ridge and (b) knoll ridge.

Based on Fig. 5, overlapped with the classified slope data and the distribution data of typical loess geomorphologic types, the slope distribution status is acquired for all the types; through numerical statistics, the slope spectrum index is achieved for every type.

\subsection{Quantitative analysis for the slope spectrum}

Through use of Microsoft Excel, the slope spectrums of the typical loess geomorphologic types are quantitatively analysed.

Through several experiments, the tendency line for the slope spectrum is firstly acquired. In order to maintain high similarity, the function of the fourth-degree polynomial regression is chosen for the tendency prediction; under this condition, the $R^{2}$ is above 0.99 .

\subsection{Exploration to the transitional relationships among the typical loess geomorphologic types}

Based on the quantitative analysis results of the slope spectrums of all typical loess geomorphologic types, the transitional relationships can be explored among these types by

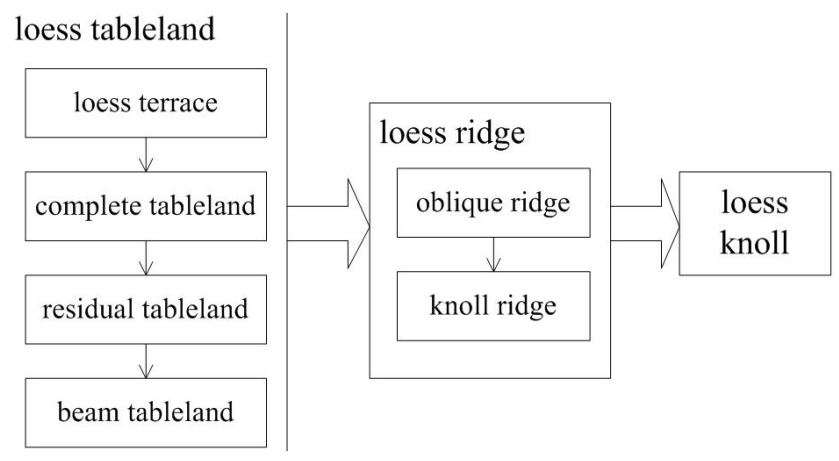

Figure 9. Transitional relationships among typical loess geomorphological types.

carefully analysing the coefficients of the regression equations and referencing the general transitional status.

\section{Results}

\subsection{The slope spectrum analysis for the typical loess geomorphologic types}

The slope class distribution status for the typical loess geomorphologic types is computed as shown in Table 2.

In Table 2 , according to the $3^{\circ}$ slope interval, the areal distribution percentages of the three loess geomorphologic types - loess tableland, loess ridge and loess knoll - are computed and listed.

Based on the computed results of Table 2, the slope spectrum indexes for the typical loess geomorphologic types are acquired as shown in Fig. 6.

In Fig. 6, the slope spectrums are mainly acquired by using slope intervals whose percentage is above $1 \%$; intervals below $1 \%$ are ignored because they are too low. Furthermore, the quantitative analysis of the slope spectrums - including the tendency lines, the regression equations and the $R^{2}-$ is conducted and given. The illustration in Fig. 6 is the same as the following slope spectrums.

Table 2 and Fig. 6 show that loess tableland is mainly distributed in the $0-9^{\circ}$ slope area, especially in the $0-3^{\circ}$ interval, and loess ridge and loess knoll are both mainly distributed in the $3-15^{\circ}$ slope area, especially in the $6-12^{\circ}$ interval. Hence, the slope spectrum index for the loess ridge is similar to that for the loess knoll, with the difference being that the loess ridge is a little steeper than loess knoll. As to the loess table, it is much flatter than the other two types; thus it has distinct slope spectrum characteristics compared to loess ridge and loess knoll.

\subsection{The slope spectrum analysis for the subtypes of the loess tableland}

The subtypes of the loess tableland are loess terrace, complete tableland, residual tableland and beam tableland. Based 
Table 4. Distribution status of the slope intervals for the subtypes of the loess ridge.

\begin{tabular}{rrrrr}
\hline \multirow{2}{*}{ Slope interval $\left(^{\circ}\right)$} & \multicolumn{2}{c}{ Oblique ridge } & \multicolumn{2}{c}{ Knoll ridge } \\
\cline { 2 - 5 } & Percentage & Grid number & Percentage & Grid number \\
\hline $0-3$ & 5 & 302457 & 6 & 423662 \\
$3-6$ & 13 & 729610 & 16 & 1102216 \\
$6-9$ & 17 & 942728 & 20 & 1390490 \\
$9-12$ & 18 & 985107 & 18 & 1268763 \\
$12-15$ & 16 & 885598 & 15 & 1011807 \\
$15-18$ & 12 & 678737 & 11 & 730640 \\
$18-21$ & 8 & 469594 & 7 & 483916 \\
$21-24$ & 5 & 293507 & 4 & 278244 \\
$24-27$ & 3 & 153879 & 2 & 134075 \\
$27-30$ & 1 & 66960 & 1 & 53610 \\
$30-33$ & 0 & 24294 & 0 & 17478 \\
$33-36$ & 0 & 7270 & 0 & 4478 \\
$36-39$ & 0 & 1653 & 0 & 884 \\
$39-42$ & 0 & 428 & 0 & 149 \\
$42-45$ & 0 & 136 & 0 & 29 \\
$45-48$ & 0 & 45 & 0 & 7 \\
$48-51$ & 0 & 10 & 0 & 1 \\
$51-54$ & 0 & 1 & & 6900449 \\
\hline Total & 100 & 5542014 & 100 & \\
\hline
\end{tabular}

on the distribution status of these subtypes, SRTM DEM data and the slope spectrum computation method, the slope distribution with a $3^{\circ}$ interval is computed for these subtypes and shown in Table 3.

Table 3 gives the slope percentage distribution of these subtypes of the loess tableland. Based on Table 3, the slope spectrum is computed and results are shown in Fig. 7.

Table 3 and Fig. 7 show that (1) loess terrace is mainly distributed in the $0-6^{\circ}$ slope area, especially in the $0-3^{\circ}$ slope area, which is the flattest subtype of the loess tableland; (2) complete tableland is mainly distributed in the $0-9^{\circ}$ slope area, especially in the $0-3^{\circ}$ slope area, which is similar to the whole loess tableland; and (3) residual tableland and beam tableland are steep and similar, they are both almost evenly distributed in the $0-21^{\circ}$ slope area, and the slope spectrums for the two subtypes are similar to that for the loess ridge.

\subsection{The slope spectrum analysis for the subtypes of the loess ridge}

The subtypes of loess ridge are oblique ridge and knoll ridge. The slope distribution status for the two subtypes is shown in Table 4.

Based on Table 4, the slope spectrum for the oblique ridge and knoll ridge is computed, and results of which are shown in Fig. 8.

From Table 4 and Fig. 8 we can see that (1) the oblique ridge and knoll ridge are both mainly distributed in the $3-18^{\circ}$ slope area, and the slope spectrum characteristics for the two subtypes are similar; (2) the oblique ridge is a little steeper than the knoll ridge; and (3) compared to oblique ridge, the slope for the knoll ridge is more similar to that for the loess knoll.

\subsection{Transitional relationship exploration for the typical loess geomorphologic types}

Based on the tendency lines and regression equations of the slope spectrums, the transitional order of the loess geomorphologic types is as follows: in the loess tableland, with the slope from flat to steep, the subtypes transition from loess terrace to complete tableland, then to residual tableland and finally to beam tableland; in the loess ridge, the subtypes transition from oblique ridge to knoll ridge. Hence, the transitional relationships among the typical loess geomorphologic types are achieved as shown in Fig. 9.

Figure 9 shows the general transitional rule of the typical geomorphologic types: from loess tableland to loess ridge, and a final transition to loess knoll. As to the subtypes, the slope change rule is adopted; thus every subtype transitions according to the elevating slope.

\section{Discussions}

\subsection{Innovations}

Based on DEM data and the topographic analysis methods, slope spectrum in previous studies has mostly been used in landform analysis, landform classification and 
geomorphologic classification (Iwahashi et al., 2001; Tang and $\mathrm{Li}, 2008$; Tang et al., 2008).

In this study, the geomorphologic boundary is determined in advance using visual interpretation and multi-source data, such as remote sensing images, DEM data, etc. (Cheng et al., 2011a, b). The accurate boundary of the loess geomorphologic types provides much more precise results for slope spectrum characteristic analysis; moreover, the transitional relationships among the typical loess geomorphologic types are explored based on the slope spectrum characteristic analysis, especially for the subtypes. Hence, this study gives a way for the relationships among the loess geomorphologic types to be studied in depth.

\subsection{Prospects}

The following aspects can be improved in future studies:

1. In this study, the boundary of the geomorphologic types is determined by multi-source data, whereas the slope spectrum characteristics are analysed based on the DEM data. If the boundary can be revised using DEM data, the slope spectrum analysis could have better results.

2. Topographic analysis in this study mainly uses the slope spectrum. In the future, more topographic indexes will be used to acquire more reasonable results.

3. The transitional relationships among geomorphologic types are explored in this study. In the future, the relation could be explored for every geomorphologic type. Through analysing the difference between the same geomorphologic type in different regions, the threshold values of the topographic indexes among the geomorphologic types can be found, and thus the fundamental difference among the geomorphologic types can be acquired.

\section{Conclusions}

The results can be summarized as the following:

1. The slope spectrum of the typical loess geomorphologic types and their subtypes are acquired by using the CGD and DEM data; then, based on the tendency line, regression equation and $R^{2}$, the slope spectrum characteristics are quantitatively analysed, which provides a way to obtain the relationships among the loess geomorphologic types.

2. The transitional relationships among the typical loess geomorphologic types and their subtypes are as follows: in general, for the typical loess geomorphologic types, the transition is from loess tableland to loess ridge and finally to loess hill. Specifically, for the subtypes of the loess tableland, there is a transition from loess terrace to complete terrace, and then to the residual tableland and finally to beam tableland. As to the loess ridge, the transition is from oblique ridge to knoll ridge.

Acknowledgements. This study was supported by the National Natural Science Foundation of China (41301469 and 41171332), the National Science Technology Support Plan Project (2012BAH28B01-03), the Qualified Personnel Foundation of Taiyuan University of Technology (tyutrc-201221a) and the Opening Foundation of LREIS. We would like to express our gratitude to the editors and the anonymous reviewers for suggestions that improved our paper.

Edited by: H. Mitasova

Reviewed by: two anonymous referees

\section{References}

Anderson, M. G., Richards, K. S., and Kneale, P. E.: The role of stability analysis in the interpretation of the evolution of threshold hillslopes, Institute of British Geographers Transactions, 5, 100-112, 1980.

Bue, B. D. and Stepinski, T. F.: Automated classification of landforms on Mars, Comput. Geosci., 32, 604-614, 2006.

Burbank, D. W.: Characteristic size of relief, Nature, 359, 483-484, 1992.

Carson, M. A.: An application of the concept of threshold slopes to the Laramie Mountains, Wyoming, Institute of British Geographers Special Publication, 3, 31-47, 1971.

Cheng, W. M., Zhou, C. H., Chai, H. X., Zhao, S. M., and Zhou, Z. P.: Research and compilation of the Geomorphologic Atlas of the People's Republic of China $(1: 1,000,000)$, J. Geogr. Sci., 21, 89-100, 2011a.

Cheng, W. M., Zhou, C. H., and Li, B. Y.: Structure and contents of layered classification system of digital geomorphology for China, J. Geogr. Sci., 21, 771-790, 2011b.

Crevenna, A. B., Rodríguez, V. T., Sorani, V., Frame, D., and Ortiz, M. A.: Geomorphometric analysis for characterizing landforms in Morelos State, Mexico, Geomorphology, 67, 407-422, 2005.

Iwahashi, J., Watanabe, S., and Furuya, T.: Landform analysis of slope movements using DEM in Higashikubiki area, Japan, Comput. Geosci., 27, 851-865, 2001.

Li, F. Y., Tang, G. A., Jia, Y. N, and Cao, Z. D.: Scale Effect and Spatial Distribution of Slope Spectrum's Information Entropy, Geo Information Sci., 9, 13-18, 2007.

Li, J. J., Zhou, C. H., and Cheng, W. M.: Geomorphologic Atlas of the People's Republic of China, Science Press, Beijing, China, 2009.

Roering, J. J., Kirchner, J. W., and Dietrich, W. E.: Evidence for nonlinear, diffusive sediment transport on hillslopes and implications for landscape morphology, Water Resour. Res., 35, 853870, 1999.

Sang, G. S., Chen, X., Chen, X. N., and Che, Z. L.: Formation model and geomorphic evolution of loess hilly landforms, Arid Land Geogr., 30, 375-380, 2007.

Strahler, A. N.: Quantitative slope analysis, Geol. Soc. Am. Bull., 67, 571-596, 1956. 
Tang, G. A. and Li, F. Y.: Landform Classification of the Loess Plateau Based on Slope Spectrum from Grid DEMs, Advances in Digital Terrain Analysis, edited by: Zhou, Q. M., Lees, B., and Tang, G. A., Springer Berlin Heidelberg, 107-124, 2008.

Tang, G. A., Ge, S. S., Li, F. Y., and Zhou, J. Y.: Review of Digital Elevation Model (DEM) Based Research on China Loess Plateau, J. Mountain Sci., 2, 265-270, 2005.

Tang, G. A., Li, F. Y., Liu, X. J., Long, Y., and Yang, X.: Research on the slope spectrum of the Loess Plateau, Sci. China Ser. E: Technol. Sci., 51, 175-185, 2008.
Wang, C., Tang, G. A., Li, F. Y., Zhu, X. J., and Jia, Y. N.: The Uncertainty of Slope Spectrum Derived from Grid Digital Elevation Model, Geo. Information Sci., 10, 539-544, 2008.

Wolinsky, M. A. and Pratson, L. F.: Constraints on landscape evolution from slope histograms, Geology, 3, 477-480, 2005.

Zhou, Y., Tang, G. A., Yang, X., Xiao, C. C., Zhang, Y., and Luo, M. L.: Positive and negative terrains on northern Shaanxi Loess Plateau, J. Geogr. Sci., 20, 64-76, 2010.

Zhu, M. and Li, F. Y.: Influence of slope classification on slope spectrum, Sci. Surv. Mapping, 34, 165-167, 2009. 